\title{
IMPACT OF THE FIG CODE OF POINTS ON EXERCISE COMPOSITION IN GROUP RHYTHMIC GYMNASTICS
}

\author{
Mihaela MANOS ${ }^{1 *}$, Lavinia POPESCU ${ }^{1}$ \\ ${ }^{1}$ National University of Physical Education and Sport, Faculty of Physical Education and Sport, Bucharest, \\ Romania \\ *Corresponding author: manosmihaela@yahoo.com
}

https://doi.org/10.35189/dpeskj.2020.59.s.3

\begin{abstract}
Trends and developments in rhythmic gymnastics concern all the fundamental and detailed aspects that strategically participate in shaping a new dimension of this sport for the next Olympic cycle. The FIG Code of Points, a document that directs the activity in rhythmic gymnastics at world level, has undergone significant changes from one Olympic cycle to another. A constant priority of the specialised international body is to establish a unitary and objective line in the training of gymnasts. The changes of content in the Code of Points, in terms of specific requirements, reflect the progress made regarding the technical, artistic and executionrelated aspects. Therefore, a critical analysis is regularly needed to see the impact of regulations on the competitive performance at the end of each Olympic cycle. Competition analysis provides highly valuable data on qualitative and quantitative gains, value distribution, social impact and the higher level reached at a given time in relation to the ideal model established by the FIG Code of Points. This study aims to identify whether the regulations provided by the FIG Code of Points for the last 6 Olympic cycles have produced changes in addressing group compositions under the artistic aspect. The research was conducted on the first 8 teams in the rankings of the World Championships for the group event during the last 6 Olympic cycles. Through documentation and video recordings, we have identified the vectors that can influence the mechanisms involved in creating group compositions.
\end{abstract}

Keywords: Code of Points, requirements, compositional vectors, group event, rhythmic gymnastics.

\section{Introduction}

Since its beginnings, rhythmic gymnastics has been considered a discipline aimed to educate the body and mind through harmonious, expressive, refined movements, but also through music.

Rhythmic gymnastics combines technical, aesthetic and artistic parameters in order to reproduce an optimal model in terms of form and execution (Díaz-Pereira et al., 2014).

Due to constant endeavours, to the "revolution" in the thinking and practice of specialists from all over the world, rhythmic gymnastics has turned from a discipline that was originally focused on body expression, rhythm and dance into a top-level discipline with its own field of expertise and specific content based on a high degree of technicality, difficulty, complexity, dynamism, spectacularity, expressiveness and elegance, all of them in perfect harmony with the specificity of musical accompaniment.

However, before becoming an independent discipline and one of the most important forms of practicing the motor act, the path travelled was often difficult. Bodo-Schmid (1985) describes chronologically the most representative moments that have marked the evolution of rhythmic gymnastics. Throughout the years, the name of the discipline, its specific content, but also the scoring system have undergone several changes. If we refer to the change of its name from artistic gymnastics into modern gymnastics, this was an attempt to correctly 
express the difference in content for getting closer to the notion of competitive sport, but also to establish its orientation and way of using gymnastic actions with a pronounced aesthetic character. In this case, the adjective "modern" meant simplicity, rationality and topicality. The appropriateness of assimilating typical dance elements and using hand apparatus was carefully analysed, considering the trend manifested at that time towards a decorative handling technique, which had become artificial at a certain point. During the same period, compulsory events were gradually inserted in the technical programme of the World Championships and the value of deductions for technical faults was established.

In general, trends and developments in rhythmic gymnastics concern all the fundamental and detailed aspects that strategically participate in shaping a new dimension of this sport for the next Olympic cycle.

Competition analysis provides highly valuable data on qualitative and quantitative gains, value distribution, social impact and the higher level reached at a given time in relation to the ideal model established by the FIG Code of Points.

\section{Scoring system in the FIG Code of Points}

A constant priority of the specialised international body is to establish a unitary and objective line in the training of gymnasts. For this purpose, the Technical Committee drew up the first Code of Points in 1970. Through the content of its subsequent editions, which was regularly supplemented and improved, the Code of Points has become a fundamental international document including a set of technical and organisational issues that confer a unique interpretation to the specific components of competitive rhythmic gymnastics.

Until 1996, judging the composition of exercises consisted in the overall evaluation of their technical and artistic value. At the request of national federations to benefit from an objective scoring method and see a part of the requirements supressed in order to allow coaches to freely express their creativity and fantasy, the FIG/RG Technical Committee reorganised judging in rhythmic gymnastics by radically changing the scoring system. To this end, technical scoring sheets were drawn up for each group of body elements, which were systematised according to their degree of difficulty.

The regulations imposed by the International Code of Points have led specialised technicians to express different and often critical points of view. According to Bobo-Arce and Sierra-Palmeiro (1998), the body difficulty presented by the International Gymnastics Federation (FIG) is ambiguous and does not define appropriate criteria-based actions to be performed by rhythmic gymnasts; thus, movements involving qualitative and quantitative requirements are often placed in the same category or level of difficulty, hence the lack of compositional variety. Bauch (2001) believes that the judging system should focus on the aesthetic and technical evaluation, and the analysis of competition routines should be oriented towards the qualitative content rather than the rules of the Code of Points, which would allow different approaches to the routine composition.

Between 2009 and 2012, the Code of Points increases technical requirements, as well as the number and value of difficulties performed separately or unitarily along with handling actions in contact with the apparatus or while losing contact with it, such as isolated throws or throws with exchange of apparatus. Although previous experience has shown that this 
orientation does not support the artistic performance, it has been accepted because it represents an advantage in terms of objectifying the scoring system. (Manos \& Popescu, 2014) In our opinion, this regulation had consequences on the choreographic choice, the principle of economy being visibly used in organising the workspace. Some artistic requirements were less taken into account and, in most cases, improperly evaluated, which has led coaches to address the routine organisation according to the technique and the execution quality, considering that these two elements are the only determinants of the composition by which they will reach the maximum score.

Liviotti and Hökelmann (2012) state that quantitative parameters do not play a fundamental role in earning the first three places in the final ranking, arguing that the most successful choreography does not necessarily include the highest number of quantitative parameters; thus, for the objectification of performance and a more exhaustive analysis of choreography, qualitative parameters must also be taken into account.

Updates to the Code of Points are aimed to increase the complexity of compositions and the degree of coordinating body difficulty with various forms of handling the apparatus depending on its characteristics (Ávila-Carvalho et al., 2011).

The 2013-2016 Code of Points marks a profound change in competitive rhythmic gymnastics. O series of criteria related to both the scoring system and specific requirements were revised after the London Olympics (Hashimoto et al., 2017). Significant changes were made to the artistic evaluation criterion. Evaluating the artistic aspects (unity of composition, interaction between music and movement, body expression and variety in using space) of the routine becomes the responsibility of the execution jury. The initial form of evaluating the artistic component losses its usefulness and undergoes significant changes. (Toledo \& Antualpa, 2016)

The classification of body difficulty elements proposed by Lebre (2011) to be adopted by FIG in the 2013-2016 Olympic cycle allowed a better analysis of the routine content. The classification was based on fundamental motor skills and the level of technical difficulty and complexity in rhythmic gymnastics.

Another element of novelty present in the 2013-2016 Code pf Points is music, which can be interpreted by one or several instruments, including the voice used as an instrument. The impact of this rule was analysed after the Rio 2016 Olympics (Toledo et al., 2018).

The current 2017-2020 Code of Points brings changes in the quantification of the structure related to judging the difficulty criterion and the artistic sub-criterion.

Several studies reflect the interest of specialists in identifying the effects induced by the changes in the Code of Points on some performance indicators in rhythmic gymnastics. The need to deepen this issue that can pave the way for higher performance is highlighted by Ávila-Carvalho et al. (2012), Leandro et al. (2017), Hökelmann et al. (2012), Massidda and Calò (2012), Bučar et al. (2013).

After analysing 13 World Championships, Sierra-Palmeiro et al. (2019) find that changes in the Code of Points have affected differently both the number of technical elements and the final score for each apparatus.

Investigating the composition of group routines and the most effective evaluation methods for the artistic component based on scoring rules was a challenge for many specialists in the field (Uratani, 2012; Uratani, 2014). 
An important aspect in creating compositions refers to the use of various body difficulty actions in synchrony with those specific to each apparatus. The limited variety in choosing body difficulties for the composition of group routines has often led to monotony and compromised their artistic value (Ávila-Carvalho et al., 2012).

\section{Research purpose}

The current study is a continuation of a research conducted by us in 2014 and is focused on the descriptive analysis of changes in the content of the Code of Points as regards the composition of group routines.

This research aims to identify whether the regulations provided by the FIG Code of Points for the last 6 Olympic cycles have produced changes in addressing group compositions under the artistic aspect. We chose to verify the same compositional vectors specific to the artistic criterion as in our previous study for being able to draw coherent conclusions.

\section{Research tasks}

- Establishing compositional benchmarks that can help to meet the requirements of an effective composition designed to ensure high-value exercises.

- Identifying compositional vectors that have undergone changes and how this is reflected in the mechanism of achieving the construction of movement forms in relation to spatial organisation forms.

\section{Methodology}

The methods used were documentation, observation and recording, which allowed us to determine some benchmarks that could directly or indirectly influence the mechanisms involved in the achievement of artistic compositions for the group event.

Information technology gave us the opportunity to record the data and facilitated the identification and subsequent analysis of compositional elements that were the object of our study.

The research was conducted on the first 8 teams in the rankings of the World Championships for the group event during the last 6 Olympic cycles.

The study met the ethical standards used in sport and exercise science, disclosing only publicly available data (Harris \& Atkinson, 2009).

\section{Study design}

1. Identifying the regulations imposed by the Code of Points in the last 6 Olympic cycles as regards the criterion of artistic scoring for group compositions

The artistic component of compositions, although many times restricted because of the rules imposed by the Code of Points, provides the opportunity of releasing the potential for individual creation and inspiration. Constructing movement forms and their interactions is based on searching and discovering perfect harmony between two exigences: 
- the one that raises the technical difficulty at a high level;

- the one that gives meaning to the whole exercise and creates a final product by using the body, group and apparatus in a scenic design of shapes, various and logical movements consistent with the meaning, but without neglecting the importance of musical accompaniment.

Table 1 shows changes in the Code of Points as regards the criterion of artistic scoring for group compositions in the last 6 Olympic cycles, with the mention that these updates do not minimise the value of the other composition-specific determinants.

Table 1. Changes in the Code of Points as regards the criterion of artistic scoring for group compositions in the last 6 Olympic cycles

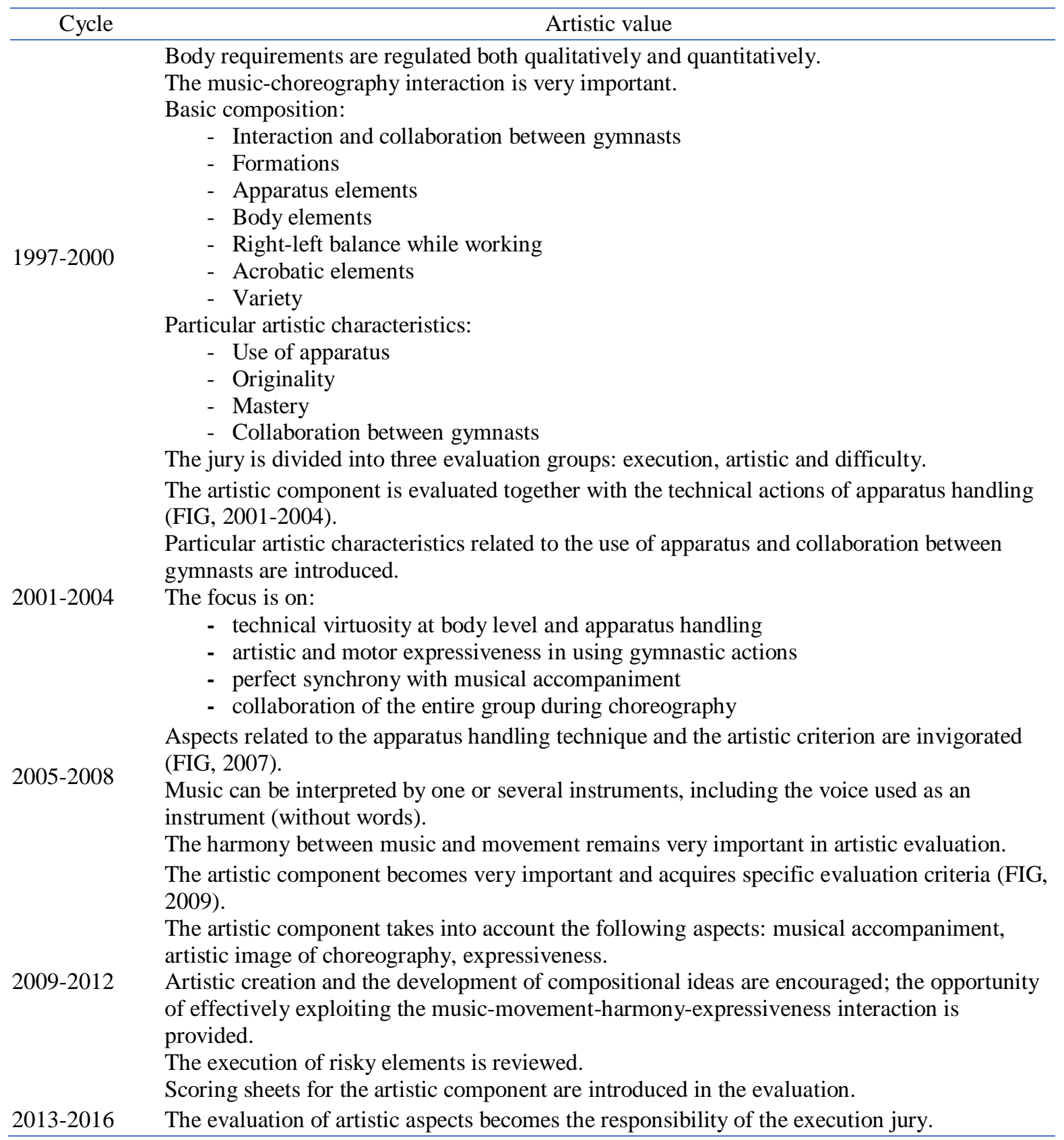


Body expression called for the participation of all body segments in movement, and together with the facial expression, should communicate the musical theme and the message of the routine composition (FIG, 2013).

Aspects regarding the variety in apparatus handling are regulated.

Music can be interpreted by one or several instruments or a musician, including the voice used as an instrument.

The artistic component is judged within the execution criterion as a distinct sub-criterion (FIG, 2018).

Starting with 2017, the artistic sub-criterion receives special attention, being evaluated independently.

The following statutory requirements are evaluated:

$>$ unity of composition

$>$ the exercise idea; the style and type of movements must reflect the compositional idea.

$>$ the use of levels and directions of body movements; apparatus directions and planes must be joint with a clear purpose.

$>$ the interaction between music and movement: body and apparatus movements must be

$2017-2020$ precisely combined respecting the musical accents and melodic line; body and apparatus movements must highlight the rhythm of the music.

$>$ changes in dynamism: energy, power, rapidity and intensity of movement must correspond to dynamic changes.

$>$ expressiveness

$>$ teamwork organisation must reflect each gymnast's homogeneous participation with cooperative spirit.

$>$ variety in organising teamwork

$>$ variety in the collaboration between gymnasts

$>$ variety in using the workspace

$>$ variety in apparatus handling actions

Collaboration between gymnasts is defined under the aspect of body and apparatus actions.

As can be seen in the above table, artistic aspects have undergone few changes in the last two Olympic cycles, which is also confirmed in a study by Toledo and Antualpa (2016).

2. Establishing compositional benchmarks

The choreography of competition routines is the dynamic expression of a composition during which the gymnast/gymnasts (group event) and the apparatus used, together with musical accompaniment, form a perfect symbiosis where the technical execution of great virtuosity and artistic/motor expressiveness define the gymnastic perfection of a group or an athlete. The content of competition events should be designed so as to meet the specific composition and execution requirements imposed by the FIG Code of Points.

Creating a choreographic composition involves difficult and laborious work that requires specialised knowledge and creative ability. The originality of imagination, emotional experience and projectivity are the main parameters of a creative design. Thus, originality can manifest from the internal plane to the external, expressive plane. (Marcus \& Neacșu, 1961)

3. Establishing specific requirements for artistic group compositions

a. Composition indivisibility

A choreographic composition is indivisible and gives meaning to the entire routine, being characterised by a unitary motor discourse with an introduction, a development of the theme and a coherent conclusion; it must show unity and develop a compositional idea by using a wide range of specific actions performed through body technical elements in synchrony with those specific to each apparatus, by maximally exploiting the somatic aspect and the psychomotor abilities of gymnasts and, last but not least, by respecting their age specifics and level of technical training. 
b. Interactions between gymnasts and group work

- the typical character of the group routine is given by each gymnast's participation in group work, in a homogeneous manner and with collective spirit; from this point of view, the composition must be designed so that the idea of collaboration throughout the routine is obvious; the group exercise that does not sufficiently express this principle in the composition loses its value;

- the interactions between gymnasts and group work from a compositional point of view are present in the exchanges of apparatus and formations, various travels, but also in the execution of elements that involve good coordination with the partner.

The ways of organising group work using body elements are shown in Figure $1(a, b)$.

\section{EXECUTION ORGANISATION}

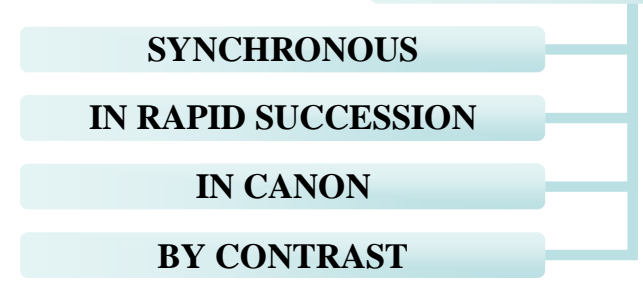

Figure 1. (a) Identical body elements for all gymnasts

\section{EXECUTION ORGANISATION}

\section{CHORAL}

\section{IN COLLABORATION}

Figure 1. (b) Different body elements for all gymnasts or subgroups

c. Compositional variety is represented by:

- Variety in choosing elements - achieved by the diversity of actions performed with apparatus (difficulty elements, connection elements) and the diversity of body elements associated with them or combinations;

- Variety in exchanging apparatus - achieved by using a varied content of technical actions with the apparatus, which are associated with body elements or technical difficulties in a spatial organisation of formations as diversified as possible;

- Variety in organising group work - achieved by using all types of collaboration and forms of creating work formations;

- Variety in dynamism - achieved by alternating fast and slow parts in the routine composition;

- Variety in occupying the workspace - manifested by using different:

o directions - forward, backward, sideways, oblique;

- possible trajectories - straight line, curve, broken line, sinusoidal line, spiral, etc.;

- space levels - low level (landing or traveling on the floor), medium level (support on one or both legs, travels, walking or running variants), high level (jumping). 
In technical terms, the aspects related to the floor area are briefly addressed in the Code of Points. However, its choreographic importance is crucial. In all manifestations of the artistic movement, space is a parameter that conditions and models the movement (Guerber-Walsh et al., 1991). As an intrinsic component of the composition, space becomes an environment where the compositional idea is developed.

\section{d. Logical connections between compositional elements}

The composition must represent an arrangement of determined shapes organised in an orderly, unitary and coherent structure that will attract through the harmony and beauty of the movements. Organising movements requires a certain sequence, continuity in the composition. The transition from one movement to another must be achieved smoothly, with a logical change of planes and/or directions.

e. Originality of choreography

Originality is the qualitative pole of creativity. The composition originality refers to including new choreographic elements with appropriate musical accompaniment, in addition to traditional or classical elements, for instance:

- new difficulties and connections coordinated with apparatus-specific actions, with or without exchange of apparatus;

- new collaboration relationships between gymnasts and apparatus;

- a new way of performing known elements;

- combinations of known elements performed in a new way;

- a new way of performing an exchange of apparatus.

c. Interaction between music and movement

Movements will be performed to various musical rhythms in an interpretation full of sensitivity, mastery and grace. Movements can be wavy, fluent, smooth or sudden, accentuated, jerky, slow or dynamic, tense or relaxed, etc., in a relationship of intimate correspondence with the character of the accompanying music.

The interaction between music and movement involves the manifestation of a good-quality rhythmic sense, a deep understanding of the musical piece, melodic line, harmony, dynamics, style and its emotional content. The coordination of movements with music requires the conscious subordination of the motor activity to the specificities of form and content of the music used. Music allows the characterisation of movements as follows:

- periodicity - defines spatial organisation;

- pace - indicates energy;

- sound climate - suggests the expression.

The role of music in rhythmic gymnastics is very important due to the organic connection between expressive motor actions and the specificity of music. Musical accompaniment ensures precision, cohesion, spatial and temporal organisation and especially expressiveness of the motor act as a result of the harmony between music and movement. In order to highlight the competitive performance of gymnasts in terms of rules imposed by the FIG Code of Points, a composition must meet the following requirements (Figure 2 and Figure 3): 


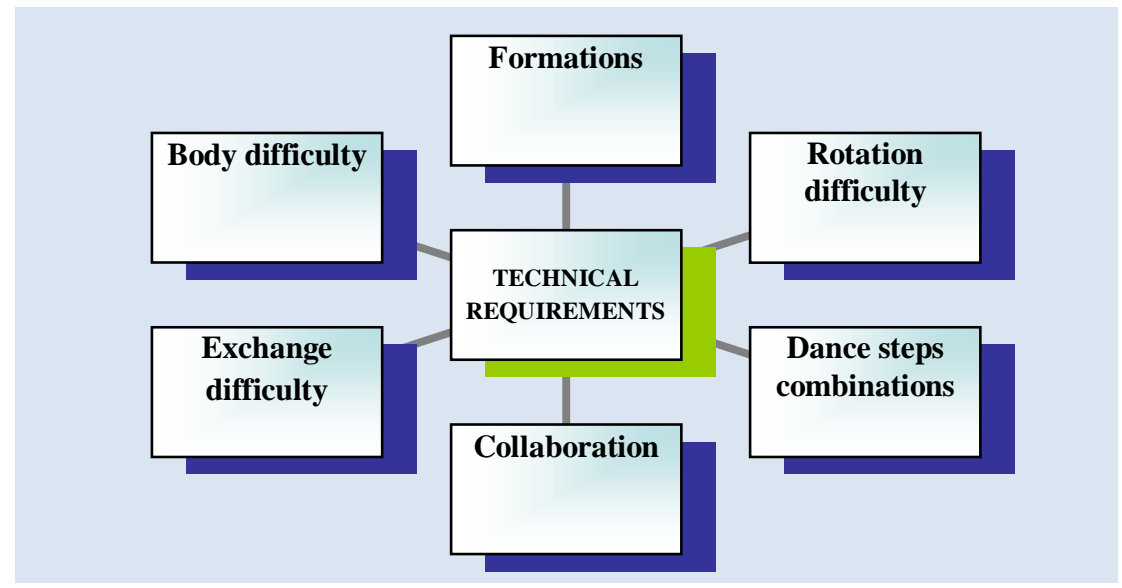

Figure 2. Technical difficulty criterion for the composition

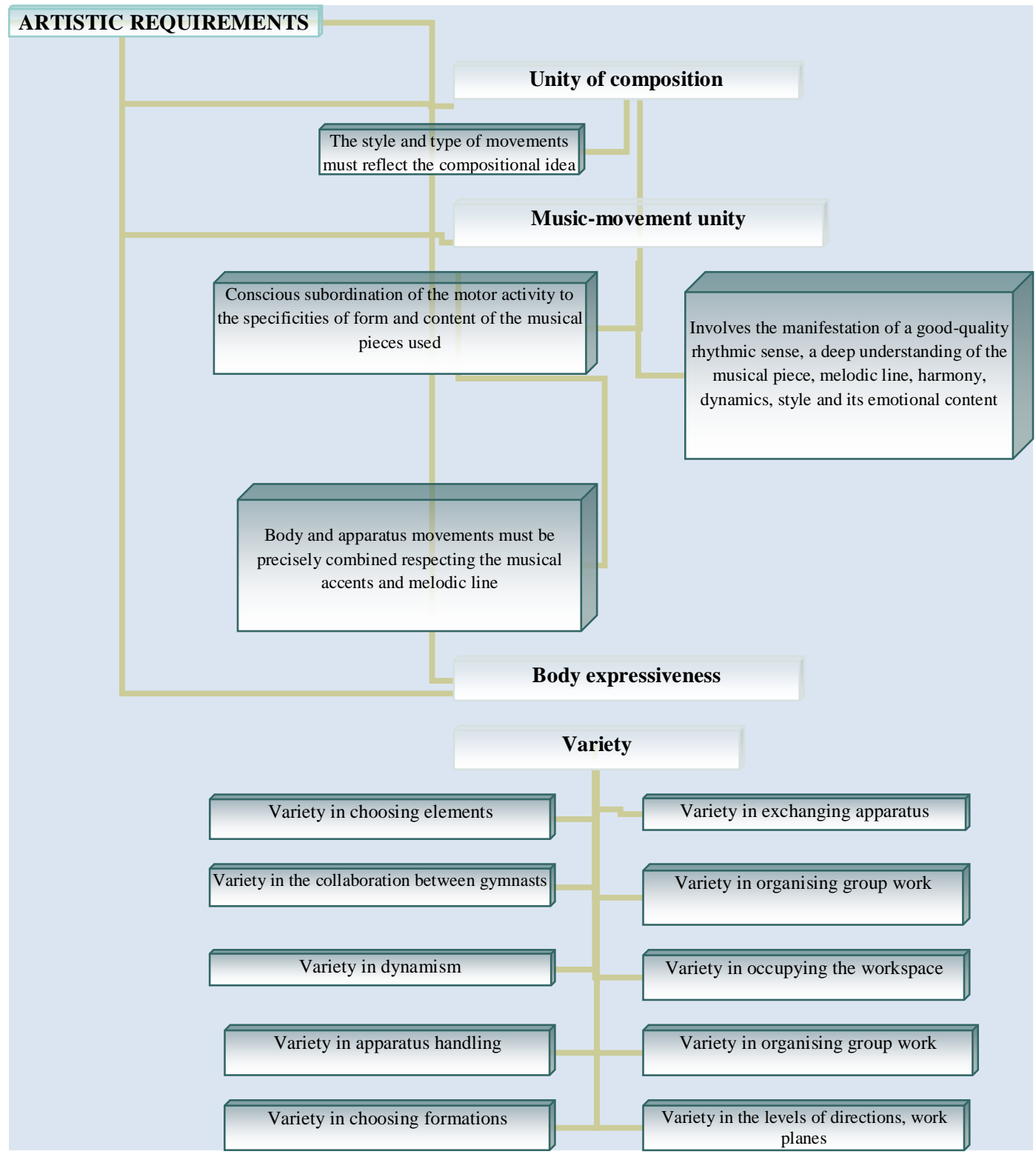

Figure 3. Artistic criterion for the composition 


\section{Results and Discussion}

The result analysis after applying "observation grids" highlights a number of general elements common to all stages, but also particular elements regarding the way of approaching compositions during the 6 Olympic cycles:

\section{General characteristics}

The composition mechanism is focused on the search of originality in combining different difficulties and the use of risky catches with the loss of visual control, which increases spectacularity associated with technical elements.

- work sub-groups and spatial cascades associated with technical elements are updated;

8 - indirect exchanges of apparatus appear, which involves new spatial organisation and creates a surprise effect;

- choreographic space becomes an important compositional variable; the duration, number, type of organisation of both the formation and work within it allow identifying the economy criteria for better "readability" of the technical content in the choreographic production;

- risky catches with the loss of visual control are used, which increases spectacularity associated with technical elements;

- classical pieces of music are mainly used; this genre is a privileged support for choreographic construction in rhythmic gymnastics.

\section{General characteristics}

The composition mechanism aims to meet the evaluation criteria for particular artistic characteristics and is focused on technical virtuosity at body level and apparatus handling.

- particular artistic characteristics mainly concern the use of apparatus and collaboration between gymnasts;

- emphasis is placed on technical virtuosity at body level and apparatus handling, and less on aspects related to the artistic and motor expressiveness;

- several elements included in the mastery criterion, which are specific for this stage of the Olympic cycle, are identified;

- despite the expressive richness and diversity of some musical pieces, many of them have a unique energetic metric;

- parameters that determine the choice of a musical piece are limited to the technical and rhythmic characteristics; in fact, such many musical pieces that can be described as monotonous are of interest in terms of expressiveness, seeking to induce a positive effect on the jury and arouse an enthusiastic reaction from the audience.

\section{General characteristics}

The composition mechanism is focused on highlighting the body technique, but

technique, the artistic component and the originality in connecting elements.

- choreographic space becomes an important compositional variable; the duration, number, type of organisation of both the formation and work within it allow identifying the economy criteria for better "readability" of the technical content in the choreographic production. 


\section{General characteristics}

The orientation towards improving the body technique and apparatus handling is maintained, and the interaction between music and movement is highlighted more efficiently.

- artistic creation and the development of compositional ideas are visible;

- the music-movement-harmony-expressiveness interaction is highlighted more efficiently;

- the transition from one formation to another meets the functionality criteria rather than purely artistic aspects;

- formations become more effective for better clarity of group collaboration (synchronous, in canon, by contrast and in rapid succession);

- musical pieces that can be described as monotonous are of interest in terms of expressiveness, seeking to induce a positive effect on the jury and arouse an enthusiastic reaction from the audience.

\section{General characteristics}

The presence of the two currents that are not yet completely divergent is noted, which reflects the permanent artistic search and highlights the physical and technical performance.

The focus is on:

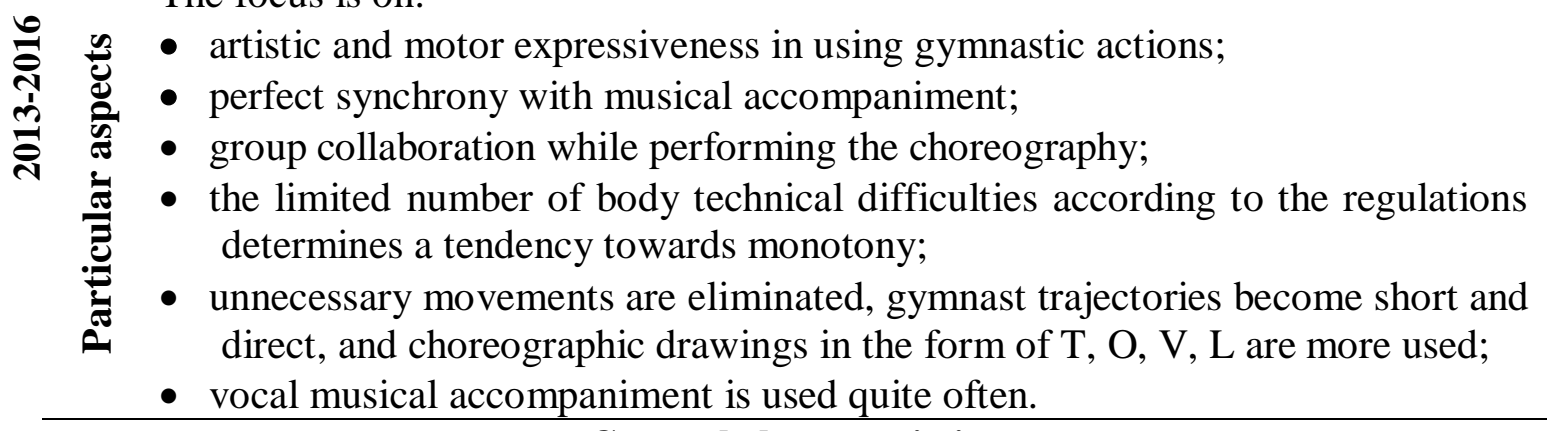

\section{General characteristics}

The artistic criterion is reconsidered, and mastery in apparatus handling is more and more visible.

- levels and directions of body movements, but also directions and planes of apparatus are often used in a unitary way;

- the interaction between music and movement: body and apparatus movements are most often precisely combined, respecting the musical accents and melodic line; not the same can be said about changes in dynamism;

- teamwork organisation often reflects each gymnast's homogeneous participation with cooperative spirit;

- more variety in organising teamwork and achieving collaboration between gymnasts;

- variety in occupying the workspace and variety in apparatus handling do not show significant changes compared to the previous Olympic cycle.

Table 2 and Table 3 show the identification of formations and the ways of spatial organisation for the group routine compositions presented at the previous editions of the World Championships: Osaka (JAP), 1999; Budapest (HUN), 2003; Patras (GRE), 2007; Mie (JAP), 2009; Kiev (UKR), 2013; Baku (AZE), 2019. 
Table 2. Types of work formations used in the group event

\begin{tabular}{lccccccc}
\hline \multicolumn{1}{c}{ Type of formation } & O & T & Y & U & L & I & V \\
\hline Studied groups (Osaka -1999) & 20 & 20 & 20 & 20 & 20 & 20 & 20 \\
Number of occurrences & $\mathbf{1 3}$ & $\mathbf{7}$ & $\mathbf{9}$ & $\mathbf{5}$ & $\mathbf{7}$ & $\mathbf{2 0}$ & $\mathbf{8}$ \\
Studied groups (Budapest - 2003) & 20 & 20 & 20 & 20 & 20 & 20 & 20 \\
Number of occurrences & $\mathbf{1 5}$ & $\mathbf{1 3}$ & $\mathbf{1 6}$ & $\mathbf{6}$ & $\mathbf{1 1}$ & $\mathbf{2 0}$ & $\mathbf{1 5}$ \\
Studied groups (Patras - 2007) & 20 & 20 & 20 & 20 & 20 & 20 & 20 \\
Number of occurrences & $\mathbf{1 7}$ & $\mathbf{1 6}$ & $\mathbf{1 5}$ & $\mathbf{7}$ & $\mathbf{1 0}$ & $\mathbf{1 9}$ & $\mathbf{1 2}$ \\
Studied groups (Mie - 2009) & 20 & 20 & 20 & 20 & 20 & 20 & 20 \\
Number of occurrences & $\mathbf{7}$ & $\mathbf{1 5}$ & $\mathbf{1 0}$ & $\mathbf{8}$ & $\mathbf{9}$ & $\mathbf{2 0}$ & $\mathbf{1 6}$ \\
Studied groups (Kiev - 2013) & 20 & 20 & 20 & 20 & 20 & 20 & 20 \\
Number of occurrences & $\mathbf{6}$ & $\mathbf{1 7}$ & $\mathbf{1 6}$ & $\mathbf{7}$ & $\mathbf{1}$ & $\mathbf{2 0}$ & $\mathbf{1 6}$ \\
Studied groups (Baku - 2019) & 20 & 20 & 20 & 20 & 20 & 20 & 20 \\
Number of occurrences & $\mathbf{7}$ & $\mathbf{1 5}$ & $\mathbf{1 6}$ & $\mathbf{1 3}$ & $\mathbf{7}$ & $\mathbf{2 0}$ & $\mathbf{1 5}$ \\
\hline
\end{tabular}

Table 3. Spatial organisation of competition routines in the group event

\begin{tabular}{rcccccccc}
\hline Period & $\begin{array}{c}\text { No. of } \\
\text { groups } \\
\text { viewed }\end{array}$ & $\begin{array}{c}\text { No. of } \\
\text { formations }\end{array}$ & Figures & Lines & $\begin{array}{c}\text { Tight } \\
\text { formations }\end{array}$ & Distribution & $\begin{array}{c}\text { Centred } \\
\text { formations }\end{array}$ & $\begin{array}{c}\text { Travelling } \\
\text { formations }\end{array}$ \\
\hline $1997-2000$ & 20 & 120 & 11 & $\mathbf{2 0}$ & 5 & 14 & $\mathbf{1 9}$ & $\mathbf{1 9}$ \\
$2001-2004$ & 20 & 140 & 17 & $\mathbf{1 9}$ & 6 & 12 & 11 & $\mathbf{2 0}$ \\
$2005-2008$ & 20 & 160 & 14 & $\mathbf{1 8}$ & 6 & 11 & $\mathbf{1 4}$ & $\mathbf{1 8}$ \\
$2009-2012$ & 20 & 180 & 10 & $\mathbf{2 0}$ & 4 & 12 & $\mathbf{1 6}$ & $\mathbf{1 7}$ \\
$2013-2016$ & 20 & 140 & 13 & $\mathbf{2 0}$ & 6 & 13 & $\mathbf{2 0}$ & $\mathbf{1 9}$ \\
$2017-2020$ & 20 & 160 & 11 & 20 & 4 & 13 & $\mathbf{2 0}$ \\
\hline
\end{tabular}

There is a tendency to use less classical figures and an orientation towards new figures that facilitate collaboration between gymnasts. Centred figures are predominant and are used for better visibility, while the line distribution of gymnasts is commonly used for distant exchanges of apparatus, as well as for synchronous or rapid-succession executions. Circle or arc formations, frequently used between 1997 and 2001, were often absent from the routine compositions of certain nations in the next Olympic cycles and rather appeared as a way of travel that responded to the need for variety in occupying the floor area or making the transition to a new formation.

The various requirements of the Code of Points lead coaches to select "useful" work formations, which often causes relatively monotonous choreography. Other compositional vectors than those related to the workspace seem to be a priority.

Compositions are organised around sequences (a sequence is a choreographic unit that gravitates around a major theme) that seek to avoid confusion so that the jury can easily recognise the technical content. Their duration may vary between 12 and 45 seconds.

Composition analysis allowed us to identify four types of sequences, which are shown in Table 4. 
Table 4. Organising compositions within choreographic sequences

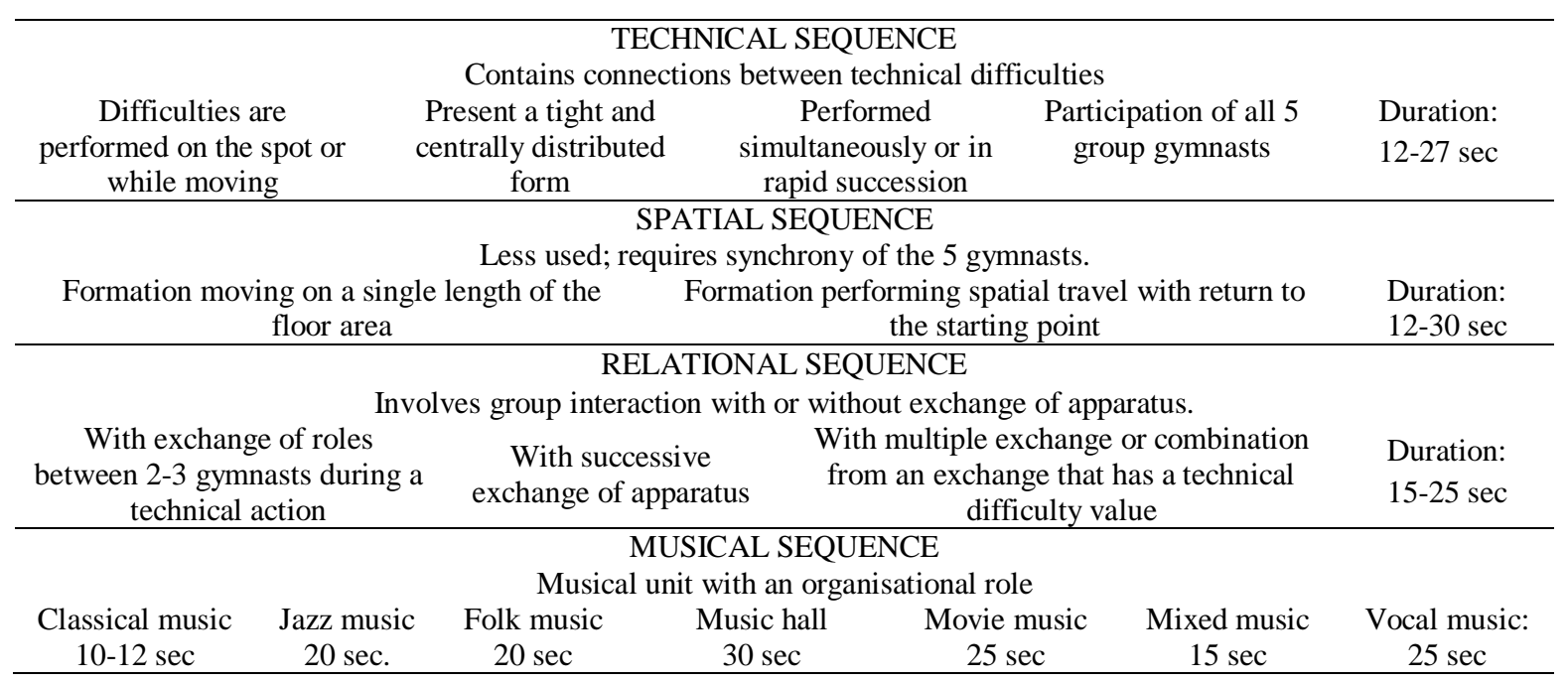

\section{Conclusion}

The analysis made in this research highlights the presence of specific elements in each Olympic cycle as regards the way of addressing the group routine compositions, which is the consequence of regular changes in the FIG Code o Points.

We believe that the artistic sub-criterion is the one that can maintain this discipline in the field of art. We make this statement because there is an opinion that rhythmic gymnastics increasingly distances itself from the art, which is due to the growing demand on the amount and complexity of body and apparatus movements; as a result, both gymnasts and coaches do their best to comply with all the technical requirements to the detriment of the artistic component, which has a lower value (Toledo, 2010).

A recent study by Sierra-Palmeiro et al. (2019) provides evidence in this regard, showing that the number of technical elements has increased in all apparatus between $6.3 \%$ and $14 \%$ over a 10-year period.

However, there has been an increase in the artistic value for the group event during the last Olympic cycle. This finding makes up hope for the achievement of exceptional performance in rhythmic gymnastics, which will undoubtedly exceed the limits predicted by specialists as regards the technical and artistic potential that exclusively characterises the representatives of this sport.

\section{References}

Ávila-Carvalho, L., Klentrou, P., da Luz Palomero, M., Klentrouand, P., \& Lebre, E. (2012). Analysis of the technical content of elite rhythmic gymnastics group routines. Open Sports Science Journal, 5, 146-153. https://doi.org/10.2174/1875399x01205010146

Ávila-Carvalho, L., da Luz Palomero, M., \& Levre, E. (2011). Estudio del valor artístico de los ejercicios de conjunto de Gimnasia Rítmica de la Copa del Mundo de Portimao 2007 y 2008 [Study of the artistic value of the group exercises at the Portimao Rhythmic Gymnastics World Cup in 2007 and 2008]. Apunts. Educación Física y Deporte, 103, 6875. https://core.ac.uk/download/pdf/41584221.pdf 
Bauch, R. (2001, 16 December). Controversial topic: "Code de Pointage”. Hamburg. http://www.gymmedia.com/FORUM/agforum/bauch_code_e.htm

Bobo-Arce, M., \& Sierra-Palmeiro, E. (1998). Una nueva propuesta de dificultades corporales en gimnasia rítmica deportiva [A new proposal for body difficulties in rhythmic sport gymnastics]. https://benthamopen.com/ABSTRACT/TOSSJ-5-146

Bodo-Schmid, A. (1985). Gimnasia ritmica deportiva [Rhythmic sport gymnastics]. Barcelona: Hispano Europea.

Díaz-Pereira, M. P., Gómez-Conde, I., Escalona, M., \& Olivieri, D. N. (2014). Automatic recognition and scoring of Olympic rhythmic gymnastics movements. Human Movement Science, 34, 63-80. https://doi.org/10.1016/j.humov.2014.01.001

FIG. (2001). 2001-2004 Code of Points: Rhythmic Gymnastics. Lausanne: FIG.

FIG. (2007). 2005-2008 Code of Points: Rhythmic Gymnastics. Lausanne: FIG. https://www.japan-rg.com/lineup/event/page/competiton/child12/item/coderg0701-e2.pdf

FIG. (2009). 2009-2012 Code of Points: Rhythmic Gymnastics. Lausanne: FIG. http://www.rsgbul.info/coderg0912-e.pdf

FIG. (2013). 2013-2016 Code of Points: Rhythmic Gymnastics. Lausanne: FIG. https://www.scottishgymnastics.org/sites/default/files/imce/disciplines/2012\%20$\% 202016 \% 20$ Rhythmic\%20Code\%20of\%20Points.pdf

FIG. (2018). 2017-2020 Code of Points: Rhythmic Gymnastics. Lausanne: FIG. https://www.gymnastics.sport/publicdir/rules/files/en_RG\%20CoP\%2020172020\%20with\%20Errata\%20Dec.\%2017.pdf

Guerber-Walsh, N., Leray, C., \& Maucouvert, A. (1991). Danse [Dance]. Revue EPS. https://www.revue-eps.com/fr/danse_o-6862.html

Harris, D. J., \& Atkinson, G. (2009). Ethical standards in sport and exercise science research. International Journal of Sports Medicine, 30(10), 701-702. https://doi.org/10.1055/s-0029-1237378

Hashimoto, M., Kida, N., \& Nomura, T. (2017). Characteristics of Women's Rhythmic Gymnastics from the perspective of "body difficulty" and performance time. Advances in Physical Education, 7(3), 260-273. https://doi.org/10.4236/ape.2017.73021

Hökelmann, A., Breitkreutz, T., \& Livioty, G. (2012). Changes in performance structure during group competitions in rhythmic gymnastics. In M. Peters \& P. O. Donoghue (Eds.), Book of Abstracts of the World Congress of the Performance Analysis of Sport (Vol. IX, p. 99). Worcester: University of Worcester. https://www.sportsci.org/2012/WCPAS_IX_Abstracts.pdf

Leandro, C., Ávila-Carvalho, L., Sierra-Palmeiro, E., \& Bobo-Arce, M. (2017). Judging in rhythmic gymnastics at different levels of performance. Journal of Human Kinetics, 60(1), 159-165. https://doi.org/10.1515/hukin-2017-0099

Lebre, E. (2011). Technical principles for the new framework: Crossroads to the future. Switzerland: International Federation of Gymnastics Scientific Commission.

Liviotti, G., \& Hökelmann, A. (2012). Quantitative choreography analysis of the group competition medallists at the Rhythmic Gymnastics World Championship 2011. International Journal of Performance Analysis in Sport, 12(2), 246-257. https://doi.org/10.1080/24748668.2012.11868597

Manos, M., \& Popescu, L. (2014). The impact induced by the 2009-2012 FIG Code of Points on the artistic compositions in rhythmic gymnastics group event. Procedia - Social and Behavioural Sciences, 117, 300-306. https://doi.org/10.1016/j.sbspro.2014.02.217

Marcus, P., \& Neacșu, Gh. (1961). Particularitățile și rolul reprezentărilor în creația actorului dramatic [The characteristics and role of representations in the dramatic actor's creation]. Revista de Psihologie, 2, 11-15. 
Massidda, M., \& Calò, M. C. (2012). Performance scores and standings during the 43rd Artistic Gymnastics World Championships 2011. Journal of Sports Sciences, 30(13), 1415-1420. https://doi.org/10.1080/02640414.2012.710759

Sierra-Palmeiro, E., Bobo-Arce, M., Pérez-Ferreirós, A., \& Fernanández-Villarino, M. (2019). Longitudinal study of individual exercises in elite rhythmic gymnastics. Frontiers in Psychology. https://doi.org/10.3389/fpsyg.2019.01496

Toledo, E. (2010). Estética e beleza na ginástica rítmica [Aesthetics and beauty in rhythmic gymnastics]. In M. Nunomura \& M. H. Tsukamoto (Eds.), Fundamentos das ginásticas (pp. 19-44). Barueri: Phorte.

Toledo, E., \& Antalupa, K. (2016). The appreciation of artistic aspects of the Code of Points in rhythmic gymnastics: An analysis of the last three decades. Revista Brasileira de Educação Física e Esporte, 30(1). https://doi.org/10.1590/1807-55092016000100119

Toledo, E., Oliveira, M., Scarabelim, M. L., \& Assumpção, B. (2018). The impact of the change in the musical attributes of the Code of Points (2013-2016) on the routines in rhythmic gymnastics of the Rio 2016 Olympic Games. Science of Gymnastics Journal, 10(3), 421-435.

https://search.proquest.com/openview/ddcb954042a326f0131f0a13529112bb/1?pqorigsite $=$ gscholar \&cbl $=666318$

Uratani, I. (2012). Criticism against scoring rules for rhythmic sportive gymnastics: Focusing on physical flexibility. Bulletin of Nippon Sport Science University, 40, 57-68.

Uratani, I. (2014). A study on the relationship between rhythmic gymnastics and art: A mistake of distinguishing objective and beauty sports. Nippon Sport University Research, $3,1-9$. 